\title{
Honey as an Adjuvant Therapy in Acute Potassium Hydroxide Poisoning in Rats
}

\author{
Niveen A. Shehata ${ }^{*}$, Doaa M. El-Gharbawy ${ }^{1}$, \\ Reda H. Elbakary ${ }^{2}$ and Ahmed A. Hashem ${ }^{1}$ \\ ${ }^{1}$ Forensic Medicine \& Clinical Toxicology, ${ }^{2}$ Departments, Faculty of Medicine, \\ Tanta University, Egypt \\ *Corresponding author
}

\begin{abstract}
A B S T R A C T
Caustic ingestion is a significant medical problem and honey has been used effectively for treatment of different wounds. It was to assess the role of honey as an adjuvant therapy in

Keywords

Caustic, Honey, Histopathology, Mean $\mathrm{pH}$ and Mean ulcer index

Article Info

Accepted:

10 August 2020

Available Online:

10 September 2020 acute ingestion of potassium hydroxide $(\mathrm{KOH})$ in adult male albino rats. 160 adult male albino rats were randomly divided into 8 groups: gp 1 (-ve control), gp 2 (+ve control), gp 3 ( $\mathrm{KOH}$ and acetaminophen), gp 4 ( $\mathrm{KOH}$ and standard treatment), gp 5 (KOH and honey) and gp 6 (KOH and standard treatment plus honey). All groups were subdivided into 2 subgroups according to sacrificing time at the end of $1^{\text {st }}$ week (a) or $3^{\text {rd }}$ week (b). All groups were subjected to macroscopic and histopathological examination of oesophagus and stomach, measuring the mean ulcer index and $\mathrm{pH}$ of gastric juice. Macroscopic examination of oesophagus revealed no lesions in all groups. While, gastric mucosa of subgroup 3a was atrophic with small ulcers and haemorrhagic lesions. Subgroup 4b showed nearly healed thick gastric mucosa. Subgroup $5 \mathrm{~b}$ revealed mild atrophic gastric mucosa, while, significantly healed gastric mucosa was detected in subgroup 6b. These results were confirmed by light microscopic examination of oesophagus and stomach by $\mathrm{H} \& \mathrm{E}$. Mean $\mathrm{pH}$ of gastric juice and mean ulcer index of gastric mucosa $/ \mathrm{mm}^{2}$ in subgroups $4 \mathrm{~b}, 5 \mathrm{~b}$ and $6 \mathrm{~b}$ were significantly decreased compared to corrosive groups. Using honey as an adjuvant therapy with standard treatment appeared to have a better healing effect in acute potassium hydroxide ingestion.
\end{abstract}

\section{Introduction}

Caustic ingestion is still considered a significant medical problem despite the efforts done to reduce exposure to the corrosive household products. Because of the lack of controlled studies, management of corrosive ingestion depends mainly on observational data and clinical experience (2).
Patients with minimal corrosive ingestion may be asymptomatic. Findings including; shortness of breath, hoarseness and stridor may suggest laryngeal trauma. Dysphagia, odynophagia and excessive salivation may be suggestive of esophageal damage. Moreover, vomiting, hematemesis and abdominal pain may suggest gastric damage. Continued pain, tachycardia, peritonitis, persistent 
leukocytosis, acidosis and development of pleural effusion should raise suspicion of perforation $(3,4)$.

The most common serious immediate complications that may develop after caustic ingestion include: bleeding, perforation, but late findings may include stricture formation leading to malnutrition and risk of developing malignant transformation. Also, late complications may include fistula formation; trachea-bronchial, gastro-colic or even enteroaortic (5).

Management of corrosive poisoning is mainly supportive. The initial treatment of patients after corrosive ingestion includes; hemodynamic stabilization and airway assessment. Then, standard treatment which includes: painkillers, milk, proton pump inhibitors (PPIs) and $\mathrm{H}_{2}$ blockers; gastroenterologists routinely recommend proton pump inhibitors and $\mathrm{H}_{2}$ blockers in corrosive ingestion. Antibiotics are not recommended prophylactically in the corrosive poisoning, but are used in gastrointestinal perforation (6).

Furthermore, systemic steroid ingestion may be used for prevention of oesophageal strictures associated with severe oesophageal burns. It has been revealed that the use of systemic corticosteroid remains controversial $(7,8,9)$.

However, all the current therapies are not always effective, have adverse side effects and are expensive. For this reason, identifying new potentially agents through natural sources is still essential for more effective and safe antiulcer therapy $(10,11)$.

From the ancient time and Nowadays, honey has been used for accelerating the wound healing process. It is considered an effective substance in the treatment of bedsores, ulcers and other skin infections accompanied by burns and wounds $(12,13,14)$.
Its healing activity is through prevention of infection, enhancing new tissue growth, free radical scavenging activities and antibacterial properties, as well as wound healing and antiinflammatory activities $(15,16,17,18)$. The aim of this study was to assess the effect of oral ingestion of honey as an adjuvant therapy in acute ingestion of potassium hydroxide in adult male albino rats.

\section{Materials and Methods}

\section{Animals}

This study was carried out on 160 adult male albino rats, weighing between 150 and 200 gram for each animal. They were obtained from the animal house of the Faculty of Medicine, Tanta University, Egypt. The rats were housed in suitable clean properly ventilated wire mesh cages for one week and had free access to water and a standard diet. They were exposed to 12:12 hours light/ dark cycles and room temperature between 22 and $24^{\circ} \mathrm{C}$.

The study was carried out according to the guide of care and the use of laboratory animals (19). The study design was approved by the Ethical Committee of Faculty of Medicine, Tanta University. The minimum estimated number of animals to offer valid results was used. Additionally, painless procedures were conducted with appropriate sedation.

\section{Experimental design}

The duration of the study was 3 weeks and the rats were randomly divided into 8 groups: group 1 (20 rats; -ve control group without treatment), group 2 (60 rats) divided into; group 2 I (20 rats; +ve control saline) received $1 \mathrm{ml}$ of $0.9 \%$ saline orally, group $2 \Pi$ (20 rats; +ve control acetaminophen) received intra-peritoneal (I.P) injection of 
acetaminophen once on the $1^{\text {st }}$ day in the dose of $25 \mathrm{mg} / \mathrm{kg} / \mathrm{rat}$ in a concentration of 10 $\mathrm{mg} / \mathrm{ml}(0.5 \mathrm{ml}$ for a rat $200 \mathrm{~g}$ body weight $)$, group 2Ш (20 rats +ve control honey) received oral honey in a dose of $2.5 \mathrm{~g} / \mathrm{kg} / \mathrm{rat}$ daily. Group 3 (20 rats; corrosive group) received $1 \mathrm{ml}$ of potassium hydroxide $5 \%$ once on the $1^{\text {st }}$ day orally then I.P. injection of acetaminophen once after the intake of corrosive in a dose of $25 \mathrm{mg} / \mathrm{kg} / \mathrm{rat}$. Group 4 (20 rats; corrosive treated with standard treatment) received orally potassium hydroxide once on the $1^{\text {st }}$ day in the same dose and concentration of group 2 and I.P. injection by $25 \mathrm{mg} / \mathrm{kg} / \mathrm{rat}$ of acetaminophen once then they were treated by $2 \mathrm{ml} / \mathrm{rat}$ of skimmed milk once on the $1^{\text {st }}$ day (20) and rantidine at the dose of $30 \mathrm{mg} / \mathrm{kg} / \mathrm{rat}$ once daily via an oral cannula. Group 5 (20 rats; corrosive treated with honey) received orally potassium hydroxide once on the $1^{\text {st }}$ day in the same dose and concentration of group 2 and I.P. injection by $25 \mathrm{mg} / \mathrm{kg} / \mathrm{rat}$ of acetaminophen once then they were treated by honey in a dose of $2.5 \mathrm{~g} / \mathrm{kg} / \mathrm{rat}$ daily via an oral cannula. Group 6 (20 rats; corrosive treated with standard treatment and honey) received orally potassium hydroxide once on the $1^{\text {st }}$ day in the same dose and concentration of group 2 and I.P. injection by $25 \mathrm{mg} / \mathrm{kg} / \mathrm{rat}$ of acetaminophen once after the intake of corrosive then they were treated by $2 \mathrm{ml} / \mathrm{rat}$ of skimmed milk once on the $1^{\text {st }}$ day, rantidine in a dose of $30 \mathrm{mg} / \mathrm{kg} / \mathrm{rat}$ once daily and honey in a dose of $2.5 \mathrm{~g} / \mathrm{kg} / \mathrm{rat}$ daily via an oral cannula.

All groups were subdivided into 2 subgroups according to the duration of sacrificing time at the end of $1^{\text {st }}$ week and $3^{\text {rd }}$ week (the same numerical groups; sub group a and b).

The body weight of all rats was recorded on the $1^{\text {st }}$ day before oral administration of chemicals then daily and the dose was adjusted accordingly.

\section{Samples collection}

The animals were deprived from food for 24 hours after the last treatment to ensure an empty stomach (water only was allowed). Then, the animals were anaesthetized by chloroform and sacrificed. An incision was done in the abdominal wall and the esophagus and stomach were removed. The gastric juice of each rat was collected and centrifuged to measure the $\mathrm{pH}$ using the $\mathrm{pH}$-meter. The oesophagus was opened and the stomach also was opened at the greater curvature and they were washed with $0.9 \%$ saline solution to clean away the blood.

All groups were subjected to Macroscopic examination of the oesophagus and the stomach by haematoxylin and eosin $(\mathrm{H} \& \mathrm{E})$ for the detection of any lesion in the mucosa. The length of each lesion was measured in $\mathrm{mm}$ to determine the mean ulcer index (UI). Light microscopic examination of the oesophagus and the stomach by haematoxylin and eosin $(\mathrm{H} \& \mathrm{E})$ for the detection of any lesion in the mucosa.

\section{Preparation of specimens for light microscopic examination}

Each freshly excised clean esophagus and stomach specimens were fixed in a $10 \%$ buffered formalin solution for 24 hours, dehydrated in ascending grades of alcohol and then cleared in two changes of xylol. Formalin-fixed oesophagus and stomach sections were embedded in pure soft paraffin for 2 hours at $55^{\circ} \mathrm{C}$ followed by embedding in hard paraffin. Finally, sections of 5 microns thickness were cut by the microtome and then stained by haematoxylin and eosin (H \&E).

\section{Morphometric study and statistical analysis including}

Morphometric analysis for $\mathrm{pH}$ of gastric juice by $\mathrm{pH}$ meter: Normal values of gastric juice 
$\mathrm{pH}$ in the rat are 3.2 (fed) and 3.9 (fasted) (21).

Morphometric analysis for mean ulcer index of gastric mucosa / $\mathrm{mm}^{2}$ :

The length of each lesion in the stomach (in $\mathrm{mm}$ ) was measured to determine the mean ulcer index (UI). The severity of mucosal lesions was scored as follows: no ulcer (0), small ulcer (1-2mm) (1), medium ulcer (3$4 \mathrm{~mm})(2)$, large ulcer (5-6mm) (4), and huge ulcer (> 6mm) (8). The UI was determined by adding the sum of the total of the scores and dividing by the number of animals.

\section{Statistical analysis}

The data obtained from measures of $\mathrm{pH}$ of the gastric juice and mean ulcer index of gastric mucosa $/ \mathrm{mm}^{2}$ were statistically analyzed using SPSS software version 21 then compared by ANOVA test to compare between different groups. The results were expressed as mean and standard deviation. The differences were considered statically significant if probability value $\mathrm{p}<0.05$ and highly significant if $\mathrm{p}<$ 0.001 and non-significant if $p>0.05$. This was followed by Post hoc (Bonferroni test) to assess the significance between the different groups (22).

\section{Results and Discussion}

\section{Mortality rate}

During the duration of the study we recorded the following mortality rate; in group 3 (corrosive) 6 rats died; 3 rats of them died on the $1^{\text {st }}$ day and another 3 rats died on the $2^{\text {nd }}$ day of the study.

Moreover, in treated groups 4,5,6 four rats died in each group on the $1^{\text {st }}$ day of the study. While, no deaths were recorded in the control groups (1 and 2).

\section{Gross examination of oesophageal and gastric mucosa}

The results of the present study documented no lesions of the oesophageal mucosa on its macroscopic examination in all groups.

Additionally, macroscopic examination of the gastric mucosa obtained from rats of the control groups (1 and 2) at the end of $1^{\text {st }}$ and $3^{\text {rd }}$ weeks showed normal gastric mucosa which was reddish and thick with normal rugae (Fig. 1a). On the other hand, macroscopic examination of the gastric mucosa obtained from subgroup $3 \mathrm{a}$ (corrosive group; rats were killed at the end of $1^{\text {st }}$ week) showed small rounded mucosal lesions in the form of ulcers and atrophic glazed mucosa (Fig. 1b). Subgroup 4a (corrosive treated with standard treatment; rats were killed at the end of $1^{\text {st }}$ week), subgroup 5a (corrosive treated with honey; rats were killed at the end of $1^{\text {st }}$ week), subgroup $5 \mathrm{~b}$ (rats were killed at the end of $3^{\text {rd }}$ week) and subgroup 6a (corrosive treated with standard treatment + honey; rats were killed at the end of $1^{\text {st }}$ week) showed atrophic gastric mucosa which was reddishyellow and thin with few rugae (Fig. 1c, 1e, 1f, 1g). Subgroup $4 \mathrm{~b}$ (rats were killed at the end of $3^{\text {rd }}$ week) showed reddish and thick gastric mucosa with normal rugae which was nearly healed (Fig. 1d). Subgroup 6b (rats were killed at the end of $3^{\text {rd }}$ week) showed significantly healed gastric mucosa which was reddish and thick with normal rugae, almost resembling normal gastric mucosa of the control groups (Fig. 1h).

\section{Light microscopic examination by $\mathrm{H} \& \mathrm{E}$ stain}

Examination of the sections obtained from the oesophageal mucosa of control groups (group 1; -ve control and group 2; +ve control) showed no statistical significant difference between these groups. They showed normal 
structure of the oesophagus that was formed of normal stratified squamous epithelium covered with keratin. Lamina propria was found under the epithelium which was a thin layer of connective tissue. The muscularis mucosa was quite thick and formed of muscle cells that were normally arranged. The submucosa was formed of dense connective tissue with many elastic fibers, collagen fibers, many nerves and lymphatic nodules. The muscularis propria layer was normal and composed of muscle cells (Fig. 2a).

Similarly, examination of the sections obtained from the gastric mucosa of control groups (group 1; -ve control, and group 2; +ve control) showed no statistical significant difference between these groups. They showed normal histological structure of the stomach with thick mucosa separated from the underlying submucosa by smooth muscle layer of muscularis mucosa. The lamina propria of the mucosa was occupied by tall straight gastric glands which were parallel to each other and perpendicular to the surface of the mucosa. The gastric pits were narrow and the gastric glands consisted of neck, body and base (Fig. 3a).

While, on examination of the sections obtained from the mucosa of the oesophagus showed thin layer of stratified squamous epithelium covered with thin layer of keratin and the submucosa was severely disrupted and widened (Fig. 2b). Also, examination of the sections obtained from the gastric mucosa in subgroup 3a showed focal loss of the surface epithelial cells of the stomach in some areas with an area of loss between the gastric glands with desquamated cells in it, widening of the submucosa, wide separation between the muscles in the muscle layer and a large haemorrhagic area in the serosa (Fig. 3b).

Examination of the sections obtained from subgroup 4 a revealed mild improvement with incomplete healing of the lesions in the oesophagus and stomach. Examination of the sections obtained oesophageal mucosa showed thin layer of stratified squamous epithelium which was covered with thin layer of keratin and areas of epithelial loss were found leaving single layer of cells (Fig. 2c). Additionally, examination of the sections obtained from the gastric mucosa showed separation between the gastric glands with dilated congested blood vessels and inflammatory cells in the submucosa (Fig. 3c).

Examination of the sections obtained from subgroup $4 \mathrm{~b}$ showed better improvement and healing of the lesions in the oesophagus and stomach more than subgroup 4a. Examination of the sections obtained from the mucosa of the oesophagus showed nearly normal stratified squamous epithelium which was covered with keratin, thinning of epithelium in some areas, the lamina propria and the muscularis mucosa were nearly normal and the submucosa contained some dilated congested blood vessels (Fig. 2d). Also, examination of the sections obtained from the gastric mucosa showed normal simple columnar epithelial cells and intact gastric glands with mild separation between the gastric glands (Fig. 3d). There was abnormal finding in the surface epithelial lining of the stomach in the form of polyp formation which was covered by stratified squamous epithelium with keratin (Fig. 3e).

Examination of the sections obtained from subgroup 5a showed that healing process of the lesions in the oesophagus and stomach was mild and not complete. Examination of the sections obtained from the mucosa of the oesophagus showed thin layer of stratified squamous epithelium which was covered with thin layer of keratin, the lamina propria was very thin and disrupted at some areas, the muscularis mucosa was disrupted, the 
submucosa was widened and contained congested blood vessels and there was widening in the space between the muscle (Fig. 2e). Examination of the sections obtained from the gastric mucosa showed discontinuity of the surface columnar epithelial lining of the stomach (Fig. 3f).

In subgroup $5 b$, there was incomplete healing of the lesions found in the oesophagus and stomach. Additionally, there was a common finding in this group that was inflammatory cells infiltration. Examination of the sections obtained from the mucosa of the oesophagus showed thin layer of stratified squamous epithelium which was covered with thin layer of keratin, the submucosa was widened and there was separation between the muscle layer (Fig. 2f). Also, examination of the sections obtained from the gastric mucosa showed mild separation between the gastric glands.
Also, there were inflammatory cells in the submucosa with dilated blood vessels (Fig. $3 g)$.

Meanwhile, in subgroup 6a, the healing process was faster than other subgroups (subgroup 4a and 5a) in the same period. However, healing was still incomplete and some lesions still present. Examination of the sections obtained from the mucosa of the oesophagus showed thin layer of stratified squamous epithelium which was covered with thin layer of keratin, the lamina propria was very thin, the muscularis mucosa was disrupted and the submucosa was widened (Fig. 2g). Additionally, examination of the sections obtained from the gastric mucosa showed separation between the gastric glands. There were mild inflammatory cells in the basal part of the mucosa and in the submucosa (Fig. 3h).

Table.1 The $\mathrm{pH}$ of gastric juice in different studied groups

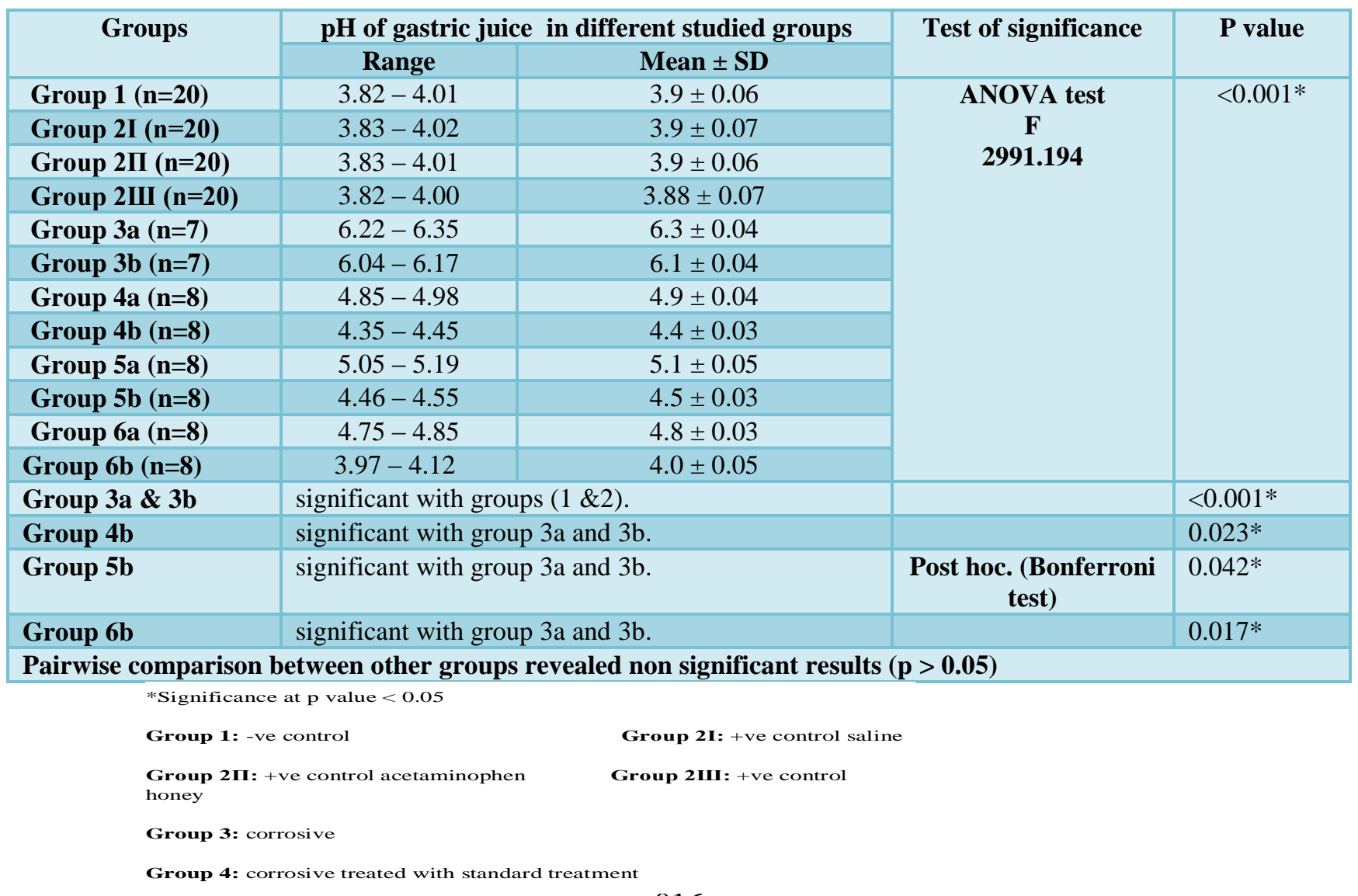


Table.2 The mean ulcer index of gastric mucosa/ $\mathrm{mm}^{2}$ in different studied groups

\begin{tabular}{|c|c|c|c|c|}
\hline \multirow[t]{2}{*}{ Groups } & \multicolumn{2}{|c|}{$\begin{array}{l}\text { Mean ulcer index of gastric } \\
\text { mucosa } / \mathrm{mm}^{2} \text { in different studied } \\
\text { groups. }\end{array}$} & \multirow[t]{2}{*}{ Test of significance } & \multirow[t]{2}{*}{ P value } \\
\hline & Range & Mean \pm SD & & \\
\hline Group $1(n=20)$ & $0-0$ & $0.0 \pm 0.0$ & \multirow{12}{*}{$\begin{array}{l}\text { ANOVA test } \\
\qquad \begin{array}{c}\text { F } \\
\mathbf{5 4 0 3 . 3 7}\end{array}\end{array}$} & \multirow[t]{12}{*}{$<0.001 *$} \\
\hline Group 2I $(n=20)$ & $0-0$ & $0.0 \pm 0.0$ & & \\
\hline Group 2П (n=20) & $0-0$ & $0.0 \pm 0.0$ & & \\
\hline Group 2WI $(n=20)$ & $0-0$ & $0.0 \pm 0.0$ & & \\
\hline Group 3a $(n=7)$ & $7.8-8.23$ & $8.02 \pm 0.15$ & & \\
\hline Group 3b $(n=7)$ & $6.88-7.54$ & $7.2 \pm 0.23$ & & \\
\hline Group 4a $(n=8)$ & $5.05-5.31$ & $5.2 \pm 0.08$ & & \\
\hline Group 4b $(n=8)$ & $1.87-2.33$ & $2.1 \pm 0.15$ & & \\
\hline Group 5a $(n=8)$ & $5.87-6.25$ & $6.1 \pm 0.13$ & & \\
\hline Group 5b $(n=8)$ & $3.45-3.98$ & $3.7 \pm 0.16$ & & \\
\hline Group 6a $(n=8)$ & $4.23-4.70$ & $4.5 \pm 0.15$ & & \\
\hline Group $6 b(n=8)$ & $0.76-1.25$ & $1.01 \pm 0.06$ & & \\
\hline Group $1 \& 2$ & \multicolumn{2}{|c|}{$\begin{array}{l}\text { significant with all other groups } \\
\text { except group } 4 \mathrm{~b}, 6 \mathrm{~b}\end{array}$} & & $<0.05^{*}$ \\
\hline Group 3a \& 3b & \multicolumn{2}{|c|}{ significant with groups $(1 \& 2)$} & & $<0.001^{*}$ \\
\hline Group 4b & \multicolumn{2}{|c|}{ significant with group $3 a$ and $3 b$} & $\begin{array}{c}\text { Post hoc. } \\
\text { (Bonferroni test) }\end{array}$ & $0.019 *$ \\
\hline Group 5b & \multicolumn{2}{|c|}{ significant with group $3 a$ and $3 b$} & & $0.033^{*}$ \\
\hline Group 6b & \multicolumn{2}{|c|}{ significant with group $3 a$ and $3 b$} & & $<0.001^{*}$ \\
\hline
\end{tabular}

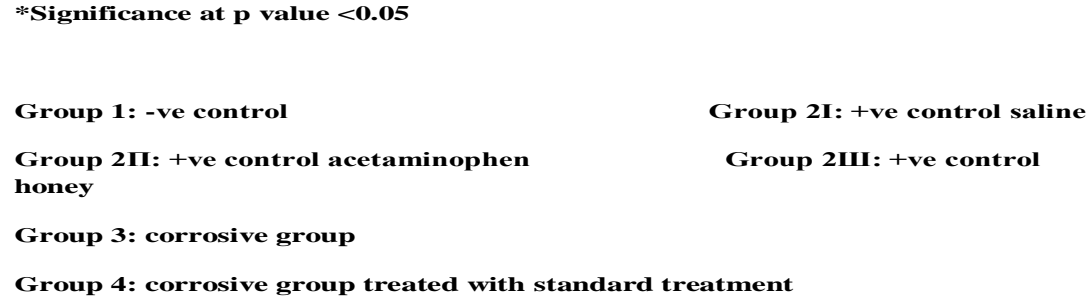


Fig.1 Gross examination of gastric mucosa in different groups; (a) control group, (b) corrosive group, (c) corrosive treated with standard treatment and killed at the end of $1^{\text {st }}$ week, (d) corrosive treated with standard treatment and killed at the end of $3^{\text {rd }}$ week, (e) corrosive treated with honey and killed at the end of $1^{\text {st }}$ week, (f) corrosive treated with honey and killed at the end of $3^{\text {rd }}$ week, $(\mathrm{g})$ corrosive treated with standard treatment + honey and killed at the end of $1^{\text {st }}$ week and (h) corrosive treated with standard treatment + honey and killed at the end of $3^{\text {rd }}$ week
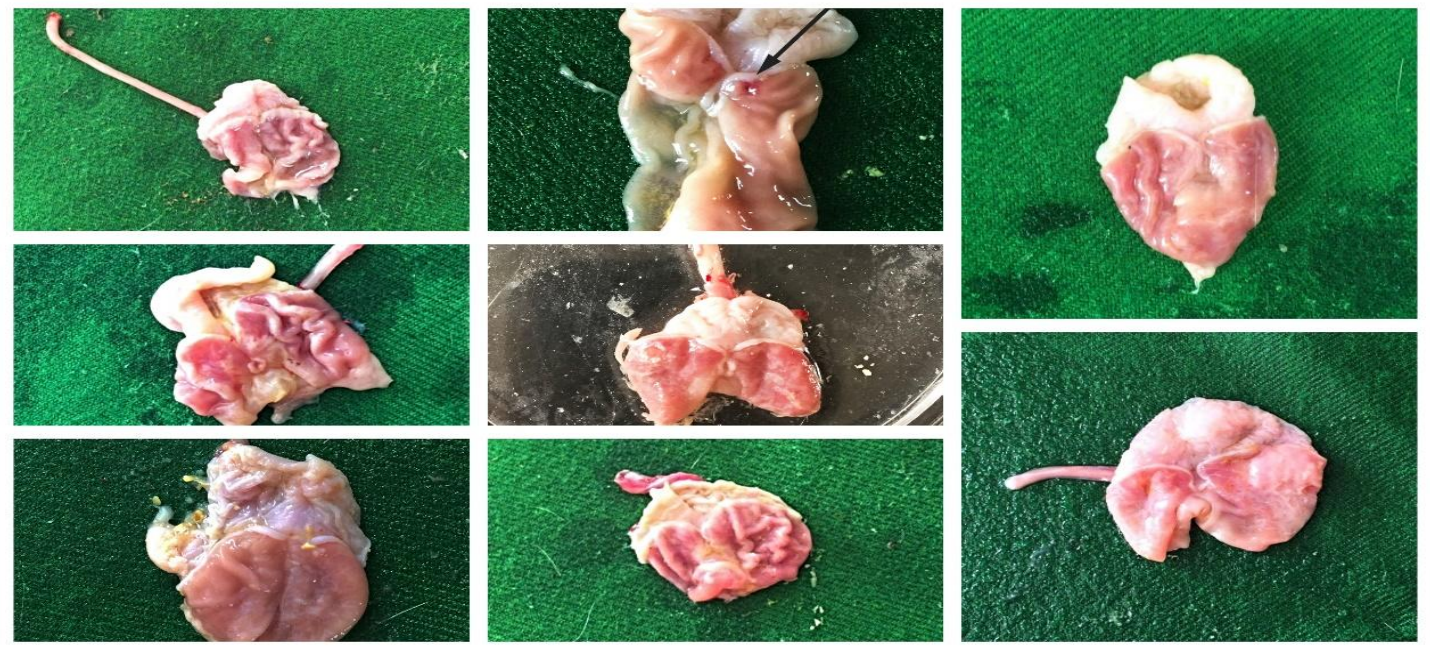

Fig.2 Light microscopic examination of oesophageal mucosa in different groups; (a) control group, (b) corrosive group, (c) corrosive treated with standard treatment and killed at the end of $1^{\text {st }}$ week, (d) corrosive treated with standard treatment and killed at the end of $3^{\text {rd }}$ week, (e) corrosive treated with honey and killed at the end of $1^{\text {st }}$ week, (f) corrosive treated with honey and killed at the end of $3^{\text {rd }}$ week, $(\mathrm{g})$ corrosive treated with standard treatment + honey and killed at the end of $1^{\text {st }}$ week and $(\mathrm{h})$ corrosive treated with standard treatment + honey and killed at the end of $3^{\text {rd }}$ week
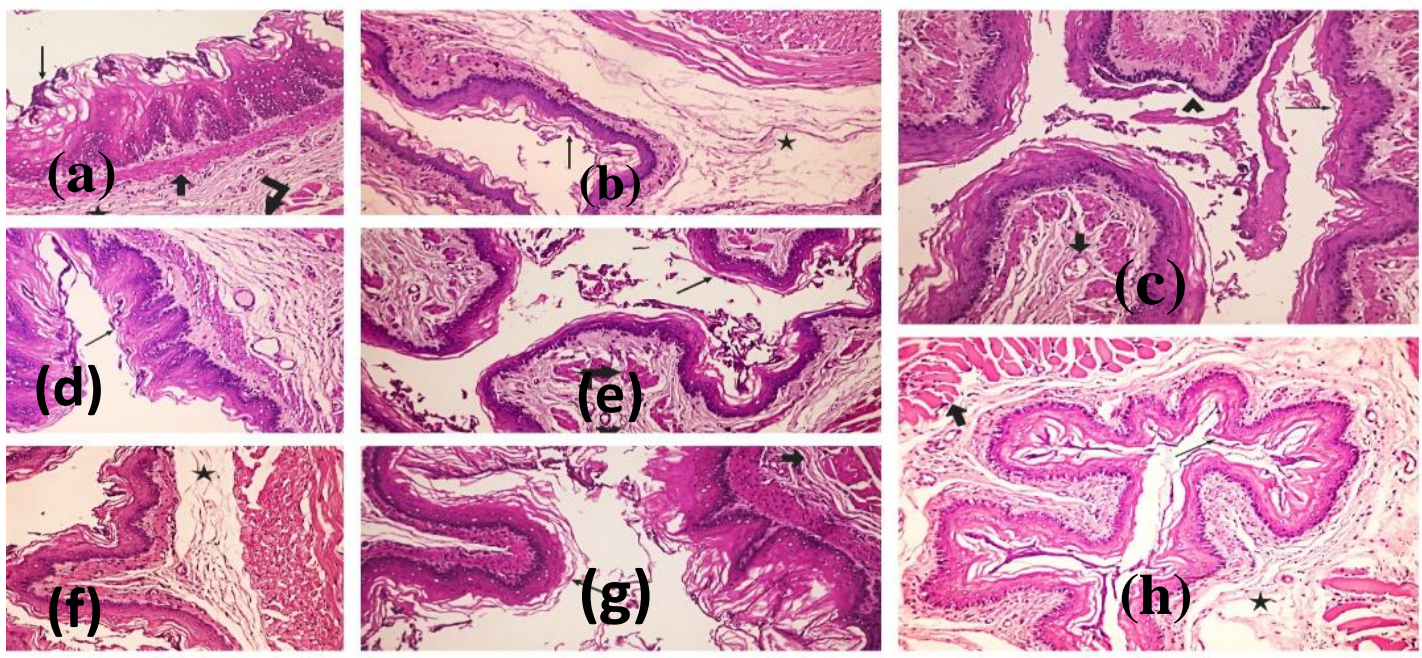
Fig.3 Light microscopic examination of gastric mucosa in different groups; (a) control group, (b) corrosive group, (c) corrosive treated with standard treatment and killed at the end of $1^{\text {st }}$ week,

(d) corrosive treated with standard treatment and killed at the end of $3^{\text {rd }}$ week, (e) corrosive treated with standard treatment and killed at the end of $3^{\text {rd }}$ week, (f) corrosive treated with honey and killed at the end of $1^{\text {st }}$ week, (g) corrosive treated with honey and killed at the end of $3^{\text {rd }}$ week, (h) corrosive treated with standard treatment + honey and killed at the end of $1^{\text {st }}$ week and (i) corrosive treated with standard treatment + honey and killed at the end of $3^{\text {rd }}$ week

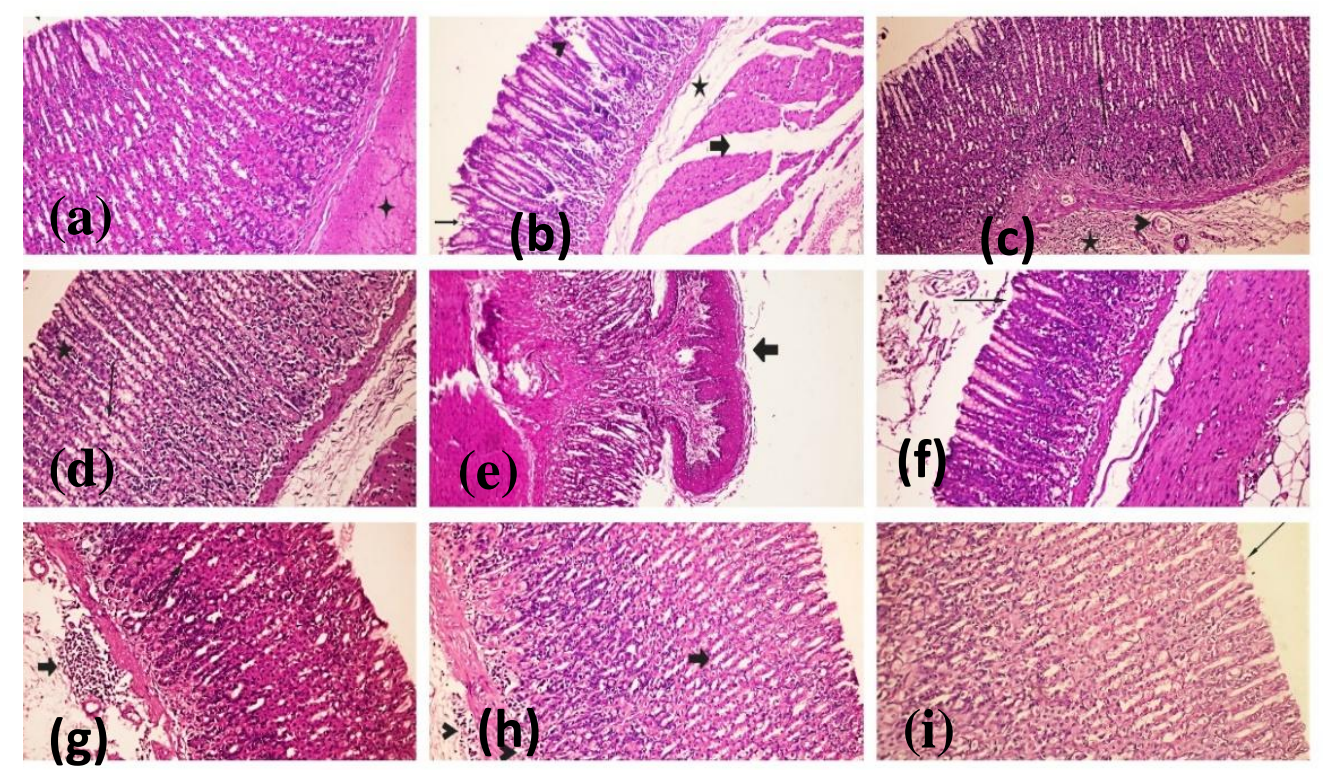

In subgroup $6 \mathrm{~b}$, complete healing of most of the lesions in the oesophagus and stomach was observed. Examination of the sections obtained from the mucosa of the oesophagus showed nearly normal stratified squamous epithelium which was covered with keratin, the submucosa and the muscle layer were nearly normal (Fig. 2h). Examination of the sections obtained from the gastric mucosa showed nearly normal columnar epithelial lining of the stomach with elongation and marked proliferation of the mucosal glands, the submucosa and the muscle layer were nearly normal (Fig. 3i).

Statistical analysis of the results for $\mathrm{pH}$ of gastric juice in the present study revealed that the mean $\mathrm{pH}$ of gastric juice in the treated subgroups; $4 \mathrm{~b}, 5 \mathrm{~b}$ and $6 \mathrm{~b}$ (rats were treated with standard treatment alone, honey alone or standard treatment and honey respectively and killed at the end of $3^{\text {rd }}$ week), were showed significant decrease when compared with corrosive groups; $3 \mathrm{a}$ and $3 \mathrm{~b}(\mathrm{p}<0.05)$ (Table $1)$.

Similarly, statistical analysis of the results for mean ulcer index of gastric mucosa $/ \mathrm{mm}^{2}$ showed that the treated subgroups; $4 \mathrm{~b}, 5 \mathrm{~b}$ and $6 \mathrm{~b}$ were significantly decreased when compared with corrosive groups; $3 \mathrm{a}$ and $3 \mathrm{~b}$ (p $<0.05)$. Moreover, subgroup $6 \mathrm{~b}$ had the minimal mean ulcer index which was so close to the control groups, followed by subgroup $4 b$ then subgroup $5 b$ (Table 2).

Corrosives are chemical agents which cause injury on contact with tissues. Exposure to corrosive agents had become a significant problem at the end of $19^{\text {th }}$ and the start of $20^{\text {th }}$ 
century especially when lye products were introduced to market as household cleaners. This increased availability of these agents was associated with an increasing incidence of accidental corrosive ingestion, especially in pediatric population (1). Honey has been effectively used in the treatment of different wound types including; burns, scratches, diabetic wounds, fistulas, leg ulcers, boils, varicose ulcers, septic and surgical wounds, cracked nipples, and wounds of the abdominal wall and perineum (14).

This study was carried out to assess the role of honey as an adjuvant therapy in acute ingestion of potassium hydroxide in adult male albino rats.

The rats in this study were killed after 1 week and 3 weeks to evaluate the healing process of different lesions by using either the standard treatment alone, honey alone or by using standard treatment and honey together. The dose of honey used in the present experiment was $2.5 \mathrm{~g} / \mathrm{kg} / \mathrm{rat}$ daily according to a study conducted by Almasaudi et al., 2017 that compared different doses of honey in the treatment of acetic acid-induced gastric ulcer in rats $(0.625 \mathrm{~g} / \mathrm{kg}, 1.25 \mathrm{~g} / \mathrm{kg}$ and $2.5 \mathrm{~g} / \mathrm{kg})$ and found that this dose was the most effective in the healing of gastric ulcers (23)

The results of the present study documented that no mortality was recorded in the control groups (1 and 2), while in corrosive group (gr3), 6 rats died; 3 rats of them died on the $1^{\text {st }}$ day and another 3 rats died on the $2^{\text {nd }}$ day of the study. Moreover, in treated groups; group 4, group 5 and group 6, it was recorded that 4 rats died in each group on the $1^{\text {st }}$ day of the study which may be due to the effect of the corrosive substance $(\mathrm{KOH})$ before starting treatment.

These results disagreed with Almasaudi et al., 2017 who studied the antioxidant and anti- inflammatory activities of manuka honey that promote healing of acetic acid-induced gastric ulcer in rats and stated that treatment with honey was safe to the animals and resulted in zero mortalities (23).

This discrepancy could be attributed to the type of corrosive agent used in the study, as acids cause coagulative necrosis decreasing the incidence of full thickness injury while alkaline agent used in our study $(\mathrm{KOH})$ causes liquefactive necrosis leading to deep tissue penetration.

Regarding the $\mathrm{pH}$ of gastric juice, the present study showed no statistical significant difference between the 4 control groups, as macroscopic and light microscopic examination of gastric mucosa revealed normal histological structure.

On the other hand, there was statistical significant increase in the $\mathrm{pH}$ of gastric juice in the corrosive groups; $3 \mathrm{a}$ and $3 \mathrm{bwhen}$ compared with those of control groups. This could be attributed to the induction of alkaline media by potassium hydroxide or loss of integrity of gastric cells by its corrosive effect which was confirmed by light microscopic examination of gastric mucosa, thus, decreasing the release of HCL.

Although, the $\mathrm{pH}$ of gastric juice in subgroups $4 \mathrm{a}, 5 \mathrm{a}$ and $6 \mathrm{a}$ were higher than those of control groups and lower than those of corrosive groups, but, no statistical significant differences were detected between these groups. This could be related to the incomplete healing process in these groups.

Meanwhile, the $\mathrm{pH}$ of gastric juice in subgroups $4 \mathrm{~b}, 5 \mathrm{~b}$ and $6 \mathrm{~b}$ showed no statistical significant differences when compared with the control groups, however, they were significantly decreased when compared with the corrosive groups. This could be attributed 
to the progress in the healing process of lesions in these groups especially in subgroup $6 \mathrm{~b}$ which revealed nearly complete healing and histological structure of stomach was almost normal confirmed by macroscopic and light microscopic examination of gastric mucosa.

These results disagreed with the results detected by Taha et al., 2015 who studied the antiulcer effect of sider honey in ethanolinduced gastric ulceration in rats and reported that the groups pre-treated with honey and the group treated with omeprazole (standard treatment) showed increase in the $\mathrm{pH}$ of the gastric fluid when compared with the ulcer group. This was in contrast with the results of our study as the etiology of gastric ulcer here was due to increase in the gastric acid secretion while the omeprazole had antiulcerogenic activity and the groups pretreated by honey were exposed to the gastroprotective effect of honey before the corrosive effect exposure (24).

Another study was done by Header et al., 2016 on the gastroprotective effects of dietary honey against acetylsalicylate induced gastric ulcer in rats and found that oral administration of acetylsalicylate decreased the $\mathrm{pH}$ of gastric juice as compared with normal rats, while oral administration of honey for 7 days after aspirin showed increase in the $\mathrm{pH}$ compared with the ulcer group. These results showed that treatment with honey had the ability to enhance the healing of peptic ulcer. This was unlike our study which found that honey alone didn't lead to complete healing; this might be explained by the difference in the type and concentration of honey used (25).

Regarding the gross examination of oesophageal and gastric mucosa; macroscopic examination of the oesophageal mucosa in this study revealed that no lesions were detected in all groups even in the corrosive groups. This was confirmed by microscopic examination of the oesophageal mucosa which revealed thinning of the oesophageal epithelium without any epithelial loss even in the corrosive group. This might be explained by the histological structure of the oesophagus in rats as it is formed of keratinized stratified squamous epithelium which differs from the oesophagus of human that is non-keratinized (26).

Macroscopic examination of the gastric mucosa obtained from the control groups showed normal gastric mucosa. On the other hand, the corrosive groups $3 \mathrm{a}$ and $3 \mathrm{~b}$ showed different degrees of gastric mucosal ulceration. While, in the treated subgroups $4 a$, $5 \mathrm{a}$ and $6 \mathrm{a}$, macroscopic examination of the gastric mucosa revealed incomplete healing of corrosive lesions. However, the treated subgroups $4 \mathrm{~b}$ and $6 \mathrm{~b}$ revealed nearly healed gastric mucosa. Unfortunately, subgroup $5 b$ (the corrosive group treated with honey) showed mild atrophic gastric mucosa which was reddish-yellow and thin with few rugae, as honey alone was not effective to complete the healing process. All macroscopic findings were confirmed by light microscopic examination of gastric mucosa in the studied groups.

These findings agreed with Yang et al., 2018 who conducted a study on the anti-ulcer effect of zinc-baicalin in acetic acid induced gastric ulcer in rats and reported that the gastric mucosa of the omeprazole group (standard treatment) showed less ulceration and less edema in the mucosa (27).

Furthermore, similar results were detected by Almasaudi et al., 2016 who studied the antioxidant, anti-inflammatory and antiulcer potential of manuka honey against ethanolinduced gastric ulcer in rats and it was found that pretreatment of ethanol injected rats with omeprazole decreased the gastric mucosal 
lesions as compared to ethanol-induced lesions and pretreatment of ethanol-injected rats with manuka honey $(2.5 \mathrm{~g} / \mathrm{kg} / \mathrm{rat})$ provided significant protection of the mucosa from ethanol-induced lesions. However, our study showed that honey alone wasn't sufficient to induce complete healing. This might be attributed to the use of honey in this study as a gastroprotective agent before induction of ulcer (28).

Regarding the mean ulcer index of gastric mucosa, the present study showed that the mean ulcer index of gastric mucosa in the 4 control groups were 0 , as the gastric mucosa was normal with no detection of any ulcers.

On the other hand, the mean ulcer index of gastric mucosa in the corrosive groups $(3 \mathrm{a}$ and $3 b)$ revealed marked increase when compared with those of the control groups, the increased gastric ulcer index in those groups might occur due to the oxidative effect of potassium hydroxide on the tissue proteins and fats, resulting in liquefactive necrosis in the form of fat saponification, protein solubilization, swelling of collagen tissue, cell membrane disruption and this led to deep tissue penetration and ulceration became more common $(29,30)$.

These findings coincided with the results of Xue et al., (2019) who conducted a study on the protective effect of polysaccharides on gastric ulcers induced by acetic acid in rats and reported that the mean ulcer index in the corrosive group was significantly increased (31).

Also, the mean ulcer index of gastric mucosa in treated groups 4a, 5a and 6ashowed marked increase when compared with the control groups and were lower than those of corrosive groups, as healing process started but, still not complete which was confirmed by the histopathological examination.
While, the mean ulcer index of gastric mucosa in treated subgroups $4 b, 5 b$ and $6 b$ were higher than those of control groups and showed statistical significant decrease when compared with the corrosive groups.

These results agreed with the results detected by Yang et al., (2018) who reported that reported that using omeprazole reduced the acetic acid-induced gastric ulcer and gastric ulcer index when compared to the corrosive group $(\mathrm{p}<0.001)(27)$.

On the other hand, Sahin et al., (2019) conducted a study on the protective effect of aqueous extract of honey in HCL/ethanol induced gastric ulcers in rats and stated that honey had gastroprotective influential effect with the most efficient degree regarding the mean ulcer index in comparison with pantazole (standard treatment). These results disagreed with the results of our study; this might be explained by the use of honey and pantazole as gastroprotective effect before inducing ulcer formation (32).

On the basis of these results it could be concluded that using honey as an adjuvant therapy with the standard treatment; skimmed milk, pain killer and rantidine appeared to have a better healing effect in the case of acute potassium hydroxide ingestion conditions which was better than the use of either the standard treatment or honey alone that had a less favorable outcome.

\section{References}

1. Riffat F, Cheng A. Pediatric caustic ingestion: 50 consecutive cases and a review of the literature. Diseases of the Esophagus. 2009; 22: 89-94.

2. Shub MD. Therapy of caustic ingestion: new treatment considerations. CurrOpinPediatr. 2015; 27: 609-613.

3. Ananthakrishnan N, Parthasarathy G, 
Kate V. Acute corrosive injuries of the stomach: A single unit experience of thirty years. ISRN Gastroenterol. 2011; 2011: 914013.

4. Ceylan H, Ozokutan BH, Gunduz F,Gozen A. Gastric perforation after corrosive ingestion. PediatrSurg Int. 2011; 27: 649-653.

5. Kluger Y, Ishay O B, Sartelli M, Katz A, et al., Caustic ingestion management: World society of emergency surgery preliminary survey of expert opinion. World Journal of Emergency Surgery. 2015; 10: 48-55.

6. Jerrold B, Frank P. Acids and alkalis. The Poisoning and Toxicology Handbook. $4^{\text {th }}$ ed. Paloucek Informa Healthcare, USA; 2007. pp. 713-719.

7. Usta M, Erkan T, Cokugras F, Urganci $\mathrm{N}$, et al., High doses of methylprednisolone in the management of caustic esophageal burns. Pediatrics. 2014; 133(6): 1518-1524.

8. Demiroren K, Kocamaz H, Dogan Y. Gastrointestinal system lesions in children due to the ingestion of alkali and acid corrosive substances. Turkish Journal of Medical Sciences. 2015; 45: 184-190.

9. Cole S, Lerner D. Caustic ingestions in children. Current Pediatrics Reports. 2018; 6:5 0-56.

10. Karaman I, Koc O, Karaman A, Erdogan $\mathrm{D}$, et al., Evaluation of 968 children with corrosive substance ingestion. Indian Journal of Critical Care Medicine. 2015; 19(12): 714-718.

11. Al Mofleh A. "Spices, herbal xenobiotics and the stomach: friends or foes?" World Journal of Gastroenterology. 2010; 16 (22): 2710 2719.

12. da Silva LM, Allemand A, Mendes D, Santos A, et al., "Ethanolic extract of roots from Arctium lappa L. accelerates the healing of acetic acid-induced gastric ulcer in rats: involvement of the antioxidant system," Food and Chemical Toxicology. 2013; 51: (1): 179-187.

13. Molan P. "Why honey is effective as a medicine," Bee World. 2001: 82(1): 2240.

14. Eteraf-Oskouei $\mathrm{T}$, Najafi $M$. "Traditional and modern uses of natural honey in human diseases: a review," Iranian Journal of Basic Medical Sciences.2013; 16: (6): 731-742, 2013.

15. Medhi B, Prakash A, Avti PK, Saikia UN, et al., Effect of manuka honey and sulfasalazine in combination to promote antioxidant defense system in experimentally induced ulcerative colitis model in rats. Indian J. Exp. Biol. 2008; 46: 583-590.

16. Halawani EM, Shohayeb MM.Shaoka and Sidr honeys surpass in their antibacterial activity local and imported honeys available in Saudi markets against pathogenic and food spoilage bacteria. Aust J Basic Appl Sci. 2011; 5(4): 187-191.

17. Hussein SZ, Mohd YK, Makpol S,Mohd YA. Gelam honey inhibits the production of proinflammatory, mediators NO, PGE(2), TNF- $\alpha$, and IL-6 in carrageenan induced acute paw edema in rats. Evid Based Complement Altern Med. 2012;2012:109636.

18. Nooh HZ,Nour-Eldien NM. The dual anti-inflammatory and antioxidant activities of natural honey promote cell proliferation and neural regeneration in a rat model of colitis. Acta Histochemica. 2016; 118(6): 588-595.

19. National Research Counsil (NRC). Guide for the care and use of laboratory animals. National Academy Press. Washington, D.C. 1996.

20. Homan CS, Maitra SR, Lane BP, Thode $\mathrm{HC}$, et al., Histopathologic evaluation of the therapeutic efficacy of water and milk dilution for esophageal acid injury. 
Academic emergency medicine. 1995; 2: 587-591.

21. McConnell EL, Basit AW, Murdan S. Measurements of rat and mouse gastrointestinal $\mathrm{pH}$, fluid and lymphoid tissue, and implications for in-vivo experiments. Journal of Pharmacy and Pharmacology. 2008; 60: 63-70.

22. Dawson B, Trapp RG. Basic and clinical biostatistics, $3^{\text {rd }}$ ed, Lang Medical Book - McGraw- Hill, New York, 2001, pp. 161-218.

23. Almasaudi SB, Abbas AT, Al-Hindi RR, El-Shitany NA, et al., Manuka honey exerts antioxidant and anti-inflammatory activities that promote healing of acetic acid-induced gastric ulcer in rats. Evidence-Based Complementary and Alternative Medicine. 2017; 2017: 5413917.

24. Taha M, Abdelwahab S, Elsanousi R, Sheikh B, et al., Effectiveness of Sidr Honey on the prevention of ethanolinduced gatroulcerogenesis: A role of antioxidant and antiapoptotic mechanism. Phcog J. 2015;7:157-164.

25. Header E, Hashish A, ElSawy N, AlKushi A, et al., Gastroprotective effects of dietary honey against acetylsalicylate induced experimental gastric ulcer in albino rats. Life Science Journal. 2016; 13(1): 42-47.

26. Uehara T, Elmore SA,Szabo KA. Esophagus and Stomach. In: Suttie AW, Leininger JR, Bradley AE, (editors) Boorman's pathology of the rat. $2^{\text {nd }} \mathrm{ed}$.
Academic press: Elsevier; 2018. pp. 3550.

27. Yang $\mathrm{H}, \mathrm{Lu} \mathrm{Y}$, Zeng XF, Li L, et al.Antichronic gastric ulcer effect of Zinc-Baicalin Complex on the acetic acid-induced chronic gastric ulcer rat model. Gastroenterology Research and Practice. 2018; 2018: 1275486.

28. Almasaudi SB, El-Shitany NA, Abbas AT, Abdel-dayem UA, et al., Antioxidant, anti-inflammatory and antiulcer potential of manuka honey against gastric ulcer in rats.Oxidative Medicine and Cellular Longevity. 2016; 2016: 3643824.

29. Chibishev A, Simonovska N, Shikole A. Post-corrosive injuries of upper gastrointestinal tract. Prilozi. 2010; 31: 297-316.

30. Contini S, Scarpignato C. Caustic injury of the upper gastrointestinal tract: a comprehensive review. World J Gastroenterol. 2013; 19: 3918-3930.

31. Xue Z, Shi G, Fang Y, Liu X, et al., Protective effect of polysaccharides from Radix Hedysari on gastric ulcers induced by acetic acid in rats. Food \& Function. 2019; 10: 3965-3976.

32. Sahin H, Kaltalioglu K, Erisgin Z, Cevher SC, et al., Protective effects of aqueous extracts of some honeys against $\mathrm{HCl} /$ ethanol-induced gastric ulceration in rats. Journal of Food Biochemistry. 2019; 43: 1-15.

\section{How to cite this article:}

Niveen A. Shehata, Doaa M. El-Gharbawy, Reda H. Elbakary and Ahmed A. Hashem. 2020. Honey as an Adjuvant Therapy in Acute Potassium Hydroxide Poisoning in Rats. Int.J.Curr.Microbiol.App.Sci. 9(09): 911-924. doi: https://doi.org/10.20546/ijcmas.2020.909.113 